\title{
Diagnóstico de viveiros da região metropolitana de Goiânia, GO, Brasil
}

\section{Diagnosis of nurseries from the metropolitan region of Goiânia, GO, Brazil}

Diagnóstico de viveros de la región metropolitana de Goiânia, GO, Brasil

Thiago Augusto ${ }^{1}$ Sybelle Barreira ${ }^{2}$

${ }^{1}$ Doutorando em Fitossanidade na Universidade Federal de Goiás (UFG). Mestre em Agronegócio pela UFG. Graduado em Ciências Biológicas pela Pontifícia Universidade Católica de Goiás (PUC/GO). Atualmente, é técnico de laboratório no Núcleo de Pesquisa em Fitopatologia (NPF/UFG). E-mail: thiagosampateles@gmail.com, ORCID: https://orcid.org/0000-0003-4031-4031

${ }^{2}$ Doutora em Recursos Florestais pela Escola Superior de Agricultura Luiz de Queiroz (ESALQ). Mestre em Engenharia Florestal pela Universidade Federal de Lavras (UFLA). Graduada em Engenharia Florestal pela UFLA. Atualmente é professora da Universidade Federal de Goiás (UFG). E-mail: sybelle.barreira@gmail.com, ORCID: https://orcid.org/0000-0003-1482-2411 
Resumo: O presente trabalho teve como objetivo diagnosticar viveiros da região metropolitana de Goiânia, com foco na forma de obtenção de sementes, quantidade de produção de mudas e canais de comercialização, tendo como parâmetro a utilização de oito espécies florestais nativas do Cerrado. Para o diagnóstico, foram realizadas visitas em 28 viveiros da região metropolitana de Goiânia, GO, e aplicado um questionário estruturado por áreas temáticas. A forma de obtenção das sementes, em sua maioria, é realizada por coleta própria dos produtores, seguida pela compra, que é realizada por meio de coletores autônomos, sem nenhum conhecimento da procedência do local de coleta, nem sobre como é realizado o beneficiamento e o armazenamento das sementes, descumprindo o que exigem as normativas da atividade.

Palavras-chave: produtos florestais não madeireiros; restauração; legislação florestal.

\begin{abstract}
The present study aimed to diagnose nurseries in the metropolitan region of Goiânia, GO, focusing on how to obtain seeds, the quantity of seedling production, and marketing channels, using as a parameter the use of eight native forest species from the Cerrado. For diagnosis, we made visits to 28 nurseries in the metropolitan region of Goiânia and applied a questionnaire structured by thematic areas. Most of the way to obtain the seeds is carried out by the producers' own collection, followed by the purchase, which is carried out through autonomous collectors, without any knowledge of the origin from the collection site, nor of how the processing and the storage of the seeds are carried out, not complying with the requirements of the activity.
\end{abstract}

Keywords: non-timber forest products; restoration; forestry legislation.

Resumen: El presente trabajo tuvo como objetivo diagnosticar viveros en la región metropolitana de Goiânia, GO, enfocándose en cómo obtener semillas, cantidad de producción de plántulas y canales de comercialización, utilizando como parámetro el uso de ocho especies forestales nativas del Cerrado. Para el diagnóstico se realizaron visitas a 28 viveros de la región metropolitana de Goiânia y se aplicó un cuestionario estructurado por áreas temáticas. La mayor parte de la forma de obtener las semillas se realiza mediante la recolección propia de los productores, seguida de la compra, que se realiza a través de recolectores autónomos, sin ningún conocimiento de la origen del sitio de recolección, ni acerca de cómo se realiza el procesamiento y almacenamiento de las semillas, no cumpliendo con los requisitos de la actividad.

Palabras clave: productos forestales no maderables; restauración; legislación forestal. 


\section{INTRODUÇÃO}

A região central do Brasil tem grande participação no agronegócio brasileiro, por isso há também grande área desmatada, por conta do descumprimento das leis ambientais. Devido a isso, o Cerrado tem grande parte de sua vegetação original desmatada, necessitando de restaurar/recuperar grande porção de sua área.

Considerando a crescente demanda por mudas para fins de restauração florestal, evidencia-se a importância de conhecer e avaliar os viveiros florestais existentes na região e a sua produção, sendo necessário avaliar se tais estabelecimentos estão cumprindo as normativas do setor, principalmente a Lei n. 10.711/2003 (BRASIL, 2004) e a Instrução Normativa n. 17 (BRASIL, 2017).

A execução de projetos visando à restauração florestal ou recuperação de áreas degradadas tem esbarrado, com frequência, na falta ou no desconhecimento da oferta regional de mudas de espécies florestais nativas. É importante que os técnicos envolvidos em tais projetos conheçam os viveiros existentes em sua região e que os viveiros possam se adequar e atender às demandas do mercado (ALONSO, 2013).

Com a finalidade de conhecer o setor de produção de mudas florestais nativas e poder nortear ações e investimentos na área, alguns trabalhos levantaram e diagnosticaram os viveiros e a produção de mudas florestais (RIOESBA, 2007; SÃO PAULO, 2011; ALONSO et al., 2014). Em alguns estados, os trabalhos de levantamento e diagnóstico de viveiros florestais e produção de mudas têm verificado a existência de alguns problemas no setor, como: a falta de infraestrutura; a baixa diversidade de espécies produzidas (RIOESBA, 2007); a obtenção de sementes (SÃO PAULO, 2011); e a dificuldade em atender a legislação que rege o setor.

Desta forma, este trabalho apresenta um diagnóstico dos viveiros da região metropolitana de Goiânia, com foco na forma de obtenção de sementes, quantidade de produção de mudas e canais de comercialização, tendo como parâmetro a utilização de oito espécies florestais nativas do Cerrado. 


\section{MATERIAL E MÉTODOS}

Para o referido diagnóstico, foram realizadas visitas em 28 viveiros entre agosto e outubro de 2016, e aplicado um questionário estruturado por áreas temáticas relacionadas à cadeia produtiva de sementes florestais. O questionário foi utilizado para coleta de informações, tais como formas de aquisição de sementes, demanda dos viveiros (quantidade de mudas vendidas/ano) e principais canais de comercialização, totalizando 19 perguntas.

A construção do questionário obedeceu às normas descritas pela Resolução do Conselho Nacional de Saúde (CNS) n. 466/12, sendo o próprio pesquisador o responsável pela aplicação. O citado instrumento foi submetido e aprovado pelo Comitê de Ética em Pesquisa (CEP) da Universidade Federal de Goiás, com Certificado de Apresentação de Apreciação Ética (CAAE) n. 54907316.0.0000.5083.

Para analisar determinados parâmetros do trabalho (forma de obtenção das sementes, produção e comercialização), foram utilizadas oito espécies florestais nativas do Cerrado, selecionadas em razão da importância econômica, ecológica e comercial e, também, por apresentarem características diversas quanto ao porte, tipos de frutos, síndromes de polinização e dispersão de sementes.

As seguintes espécies florestais foram utilizadas: jatobá (Hymenaea courbaril L.); baru (Dipteryx alata Vogel); tamboril (Enterolobium contortisiliquum [Vell.]); ipê-roxo (Handroanthus impetiginosus ([Mart. ex Dc.] Mattos); ipê-rosa ([Handroanthus heptaphyllus (Vell.] Mattos); caroba (Jacaranda cuspidifolia Mart.); pau-terra (Qualea grandiflora Mart.); aroeira (Myracrodruon urundeuva Fr. All.).

Com as informações coletadas durante a pesquisa, realizaram-se análises qualitativas e quantitativas, por meio de descrições da forma de obtenção das sementes, e traçou-se um paralelo com as recomendações técnicas exigidas em lei, evidenciando-se os gargalos dos viveiros florestais da Região Metropolitana de Goiânia. Para a tabulação dos dados e análises, foi utilizado o programa Microsoft Office Excel 2010. 


\section{RESULTADOS E DISCUSSÃO}

Alguns dos viveiros visitados, que, no contato inicial, diziam-se produtores de mudas, eram na verdade revendedores, compravam mudas de espécies nativas de alguns produtores para revender. Com este cenário, os 28 viveiros visitados diferenciaram-se entre produtores (68\%) e revendedores (32\%), e as visitas demonstraram que alguns viveiros não tinham estrutura para produção, somente para revenda, alterando a forma de análise do diagnóstico.

Com base nos municípios pertencentes na região Metropolitana de Goiânia, foram visitados 28 viveiros (apêndice II), concentrados no município de Goiânia (21), Aparecida de Goiânia (4) e Goianira (3). Todos os viveiros visitados foram georreferenciados por meio de um GPS e plotados no mapa apresentado na Figura 1.

Figura 1 - Mapa com a localização dos viveiros

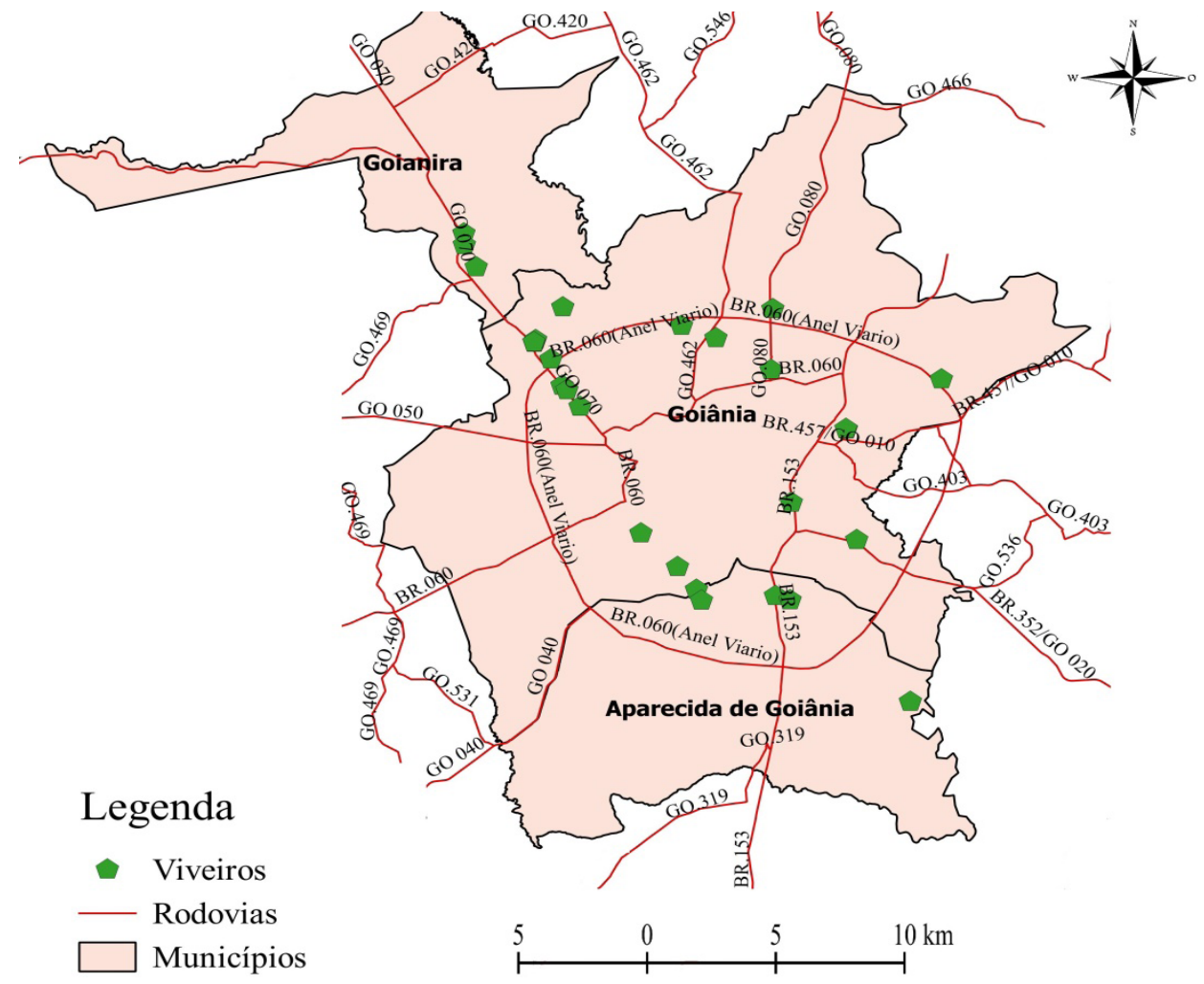

Fonte: Elaboração própria. 
Os viveiros foram divididos em classes de acordo com a quantidade produzida no ano de 2015. Para isso, foi utilizada a classificação que dividiu os produtores de mudas em três classes: pequeno (<50.000), médio (50.001 até 200.000) e grande (>200.001), com produção média entre os viveiros pertencentes a sua respectiva classe, como descritos na Tabela 1.

Tabela 1 - Produção média anual de mudas nativas por tamanho de viveiro na Região Metropolitana de Goiânia

\begin{tabular}{ccc}
\hline Classe & Quantidade de viveiros & Produção média/ano \\
\hline Pequeno $(<50.000)$ & 13 & 5.800 \\
Médio $(50.001$ a 200.000$)$ & 5 & 112.000 \\
Grande $(>200.001)$ & 1 & 450.000 \\
\hline
\end{tabular}

Fonte: Elaboração própria baseada em dados coletados no ano de 2016.

Quanto à quantidade de mudas produzidas pelos viveiristas (produtores), há uma variação muito grande entre os viveiros visitados. O menor produtor de mudas registrou 100 mudas de espécies nativas, já o maior produtor, cerca de 450.000 mudas, tendo como referência o ano de 2015, totalizando 1.084 .900 mudas nativas produzidas. Entretanto vale ressaltar que esses dados são estimativas repassadas pelos produtores, pois, durante as entrevistas, nenhum dos viveiros entrevistados recorreu a alguma planilha de controle de produção.

Silva et al. (2015) detectaram 30 viveiros na região Centro-Oeste, com produção média anual de mudas nativas de 6.181.800, sendo que, do total da região estudada, 20 viveiros pertencem ao estado de Goiás. A sistematização de informações sobre a produção dos anos anteriores pode auxiliar os viveiristas no planejamento para o próximo ano. Entretanto notou-se que não há rigor no controle sobre a produção de mudas. Em geral, todas as respostas foram obtidas de estimativas, e não de planilhas de controle, demonstrando certo grau de amadorismo no controle da produção.

Os viveiros visitados na região metropolitana de Goiânia apresentaram média de 34.306 mudas comercializadas em 2015. O maior valor comercializado foi de cerca de 300.000 mudas, e o menor valor, 70 mudas 
comercializadas. O somatório de mudas comercializadas por todos os viveiros (produtores e revendedores) foi de 926.170. Porém estes dados se sobrepõem, pois não foi questionado aos produtores qual a margem de vendas para outros viveiros, que praticam somente a revenda das mudas.

No diagnóstico realizado pela Secretaria do Meio Ambiente de São Paulo (SÃO PAULO, 2011), obteve-se o total de 40.934 .311 mudas comercializadas. Essa diferença em relação à região metropolitana de Goiânia pode estar relacionada à quantidade de locais visitados pela pesquisa no Estado de São Paulo (208 viveiros). Além disso, o estado em questão tem um mercado já consolidado, inclusive com muitos viveiros da Região Centro-Oeste adquirindo mudas do estado de São Paulo.

Nos viveiros de médio e grande porte, o principal canal de comercialização são empresas do ramo de restauração florestal (71\%) que possuem grandes projetos de recuperação ambiental, ocorrendo também compra de mudas por fazendeiros, para legalizar sua propriedade autuada por órgãos ambientais. Nos pequenos viveiros, há pouca demanda de mudas por empresas, seu principal mercado é a comunidade (29\%), principalmente de transeuntes que se dirigem aos seus sítios e fazendas e vão plantar ali um número bem pequeno de mudas, para fins de paisagismo e ornamentação.

Esses resultados corroboram aqueles encontrados no estudo realizado por Rio de Janeiro (2010), que, considerando somente os viveiros particulares, 70\% das mudas produzidas são destinadas à comercialização; $21 \%$, para uso em projetos próprios; e apenas 9\%, para doações. Em estados onde a maioria dos viveiros é particular, como no caso de São Paulo, verificou-se que aproximadamente $65 \%$ das mudas são destinadas à comercialização; $8 \%$, a doações; $27 \%$, ao uso próprio; e um percentual menor que 1\%, para a troca (SÃO PAULO, 2011).

Do ponto de vista ambiental, algumas espécies que poderiam ser desejáveis em projetos de restauração são excluídas por não terem coletas rentáveis - por exemplo, quando a espécie produz pouca quantidade de sementes ou o período de sazonalidade de produção é muito longo. Para que essas espécies raras possam ser produzidas, serão necessários, além de mudanças na legislação, incentivos econômicos para os produtores (SILVA et al. 2015). 
A diversidade de espécies nativas comercializadas pelos viveiros (Figura 2) foi questionada em um dos itens da pesquisa, e dois viveiros apresentaram a maior diversidade de espécies nativas, contrastando com um viveiro que trabalha somente com duas espécies.

Figura 2 - Diversidade de espécies comercializadas pelos viveiros da região metropolitana de Goiânia

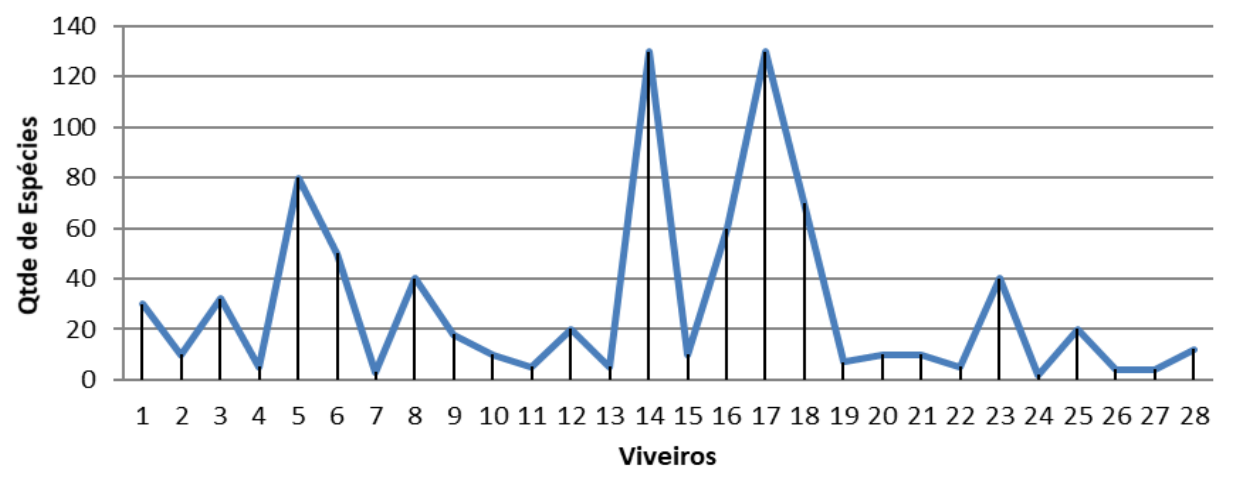

Fonte: Elaboração própria baseada em dados coletados no ano de 2016.

Os viveiros pesquisados na região metropolitana de Goiânia apresentaram, em sua maioria, baixa diversidade de espécies: 11\% dos viveiros visitados tinham alta diversidade; 18\%, média; e 71\%, baixa diversidade de espécies comercializadas. No diagnóstico nacional realizado por Silva et al. (2015), foram obtidas informações de 227 viveiros em todas as regiões do país, quanto à variedade de espécies produzidas. A Região Sudeste apresentou média de 90 espécies nativas, enquanto nas demais regiões a média de espécies produzidas nos viveiros variou de 60 a 21. A Região Centro-Oeste obteve média de diversidade de 60 espécies nativas entre os viveiros amostrados.

Quanto ao número de espécies nativas que os viveiros comercializavam no período analisado, foram encontrados valores distintos; nesse caso, estão considerados todos os viveiros, e a média foi de 32 espécies nativas, variando entre 2 e 130 espécies. Na Tabela 2, encontra-se a classificação dos viveiros quanto ao número de espécies comercializadas, seguindo o mesmo critério adotado no relatório realizado por SÃO PAULO (2011). Nas visitas, 
foi solicitada uma listagem com as espécies de cada viveiro, porém apenas um viveiro repassou essa listagem. Outros viveiros não tinham esse controle e informaram que a diversidade de espécies nativas comercializadas varia de acordo com a demanda anual do mercado.

Tabela 2 - Classificação dos viveiros na Região Metropolitana de Goiânia quanto ao número de espécies comercializadas

\begin{tabular}{ccc}
\hline Classe & Quantidade de viveiros & $\begin{array}{c}\text { Média da diversidade } \\
\text { ou do } \mathbf{n} \text {. de espécies }\end{array}$ \\
\hline Baixa $(<35)$ & 20 & 11 \\
Média (36 a 75) & 5 & 52 \\
Alta (>76) & 3 & 137 \\
\hline
\end{tabular}

Fonte: Elaboração própria baseada em dados coletados no ano de 2016.

Nas visitas realizadas, os viveiristas foram questionados sobre qual a causa da baixa diversidade das espécies. Em geral, responderam que não há demanda para diferentes espécies de mudas nativas, há mais procura por determinadas espécies que já têm venda garantida. Já nos dados obtidos em pesquisa no estado do Rio de Janeiro, a baixa diversidade de espécies é justificada pela escassez de remanescentes florestais em que a coleta de semente possa ser feita e a dificuldade de encontrar árvores matrizes de espécies mais raras (RIO DE JANEIRO, 2010).

Adaptações normativas podem ser utilizadas para aumentar a diversidade de espécies, como no estado de São Paulo, que, por meio da Resolução SMA n. 08, de 2008, da Secretaria de Meio Ambiente, exige dos projetos de restauração ecológica a utilização de, no mínimo, oitenta espécies para os plantios no estado. Essa determinação tem consequências indiretas no aumento do número de espécies produzidas nos viveiros de florestais nativas (BRANCALION et al., 2010).

Entre as espécies estudadas nesta pesquisa, todas têm importância econômica e ambiental, algumas têm utilização da madeira, outras cunho ornamental e também alimentício. Foi obtida na pesquisa a estimativa de venda de mudas das oito espécies nativas (Figura 3), como forma de entender a importância dessas espécies no comércio de mudas. 
Figura 3 - Estimativa média de vendas de mudas por espécie

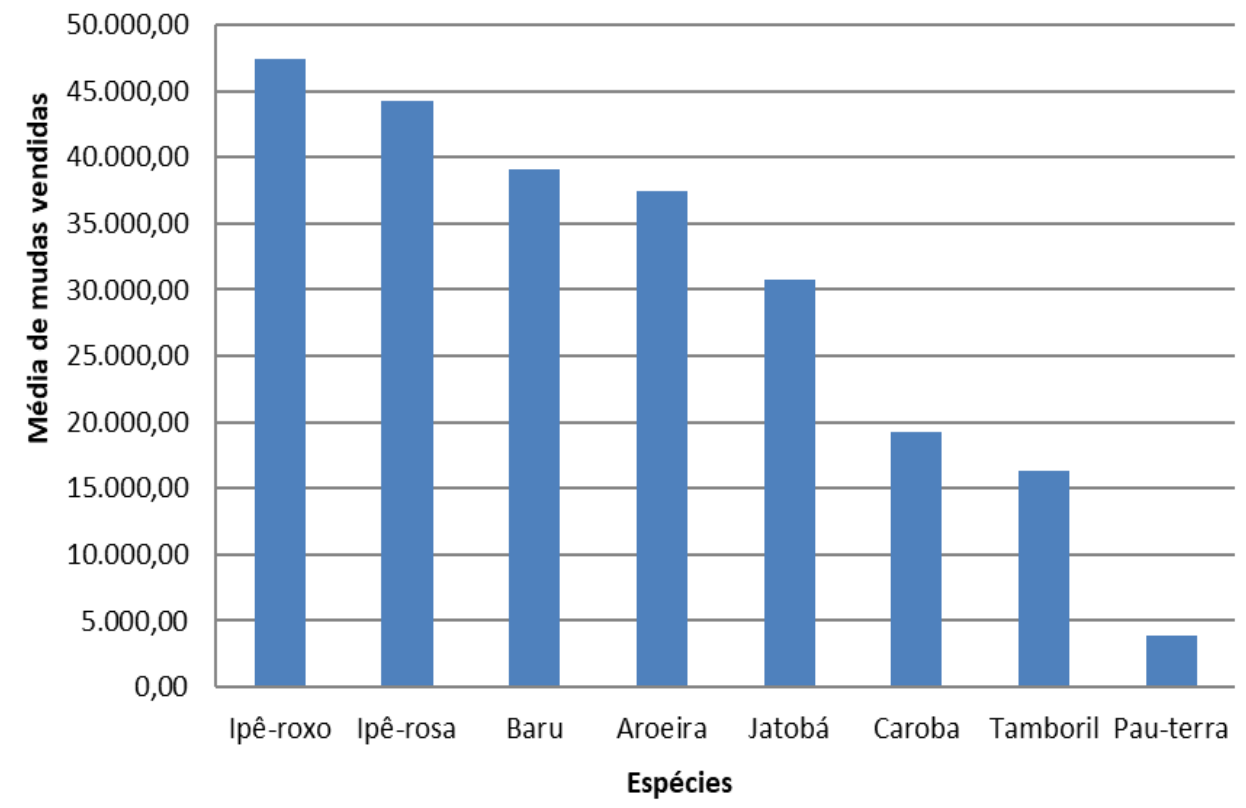

Fonte: Elaboração própria baseada em dados coletados no ano de 2016.

As espécies de ipê foram as que se destacaram nas vendas de mudas: o ipê-roxo, com 47.480 mudas por ano, e o ipê-rosa, com 44.300 mudas, utilizadas principalmente para uso ornamental e também em restauração florestal. O baru apresentou média de 39.080 mudas, demonstrando a sua importância nesse comércio. Tem sido muito utilizado em recuperação de áreas degradadas, o consumo de sua semente é bastante apreciado na região e o óleo da semente é extraído para ser usado como medicamento natural. A aroeira apresenta uma média alta de venda devido à importância de sua madeira, utilizada em muitas propriedades rurais, tendo média anual de 37.490 mudas.

A Qualea grandiflora (pau-terra) tem uma particularidade apresentada pelos produtores de mudas. Essa espécie tem certa dificuldade de desenvolvimento das mudas, segundo os viveiristas, ela tem uma boa taxa de germinação, mas, em determinado momento, seu crescimento paralisa e a planta morre; esse motivo explica a baixa comercialização dessa espécie nos viveiros visitados. 
A disponibilidade de sementes e mudas nativas é parte essencial para a implantação de projetos de restauração florestal. Conhecer regionalmente características dos viveiros e da produção de mudas, como a oferta, o potencial de produção, a qualidade, a diversidade, entre outros fatores, é importante para o planejamento estratégico de toda a cadeia produtiva da restauração florestal (ALONSO, 2013).

Após o questionamento acerca da diversidade das espécies e quantidade comercializada das espécies-alvo, foi prospectado quais os viveiros que comercializavam sementes. Assim, somente três viveiros apresentaram-se como comerciantes de sementes e relataram que isso ocorre de forma bem esporádica, não tendo impacto financeiro no mercado.

Os viveiros obtêm suas sementes de forma mista, por meio de coleta, doação e compra. Ocorre certa particularidade na obtenção de sementes, sendo que, em sete viveiros, há $100 \%$ de coleta própria e apenas um viveiro obtém $100 \%$ de suas sementes por meio de compra. Na Figura 4, está descrita a forma de obtenção de sementes pelos viveiros.

Figura 4 - Tipos de obtenção de sementes observados nos viveiros de mudas florestais localizados na Região Metropolitana de Goiânia

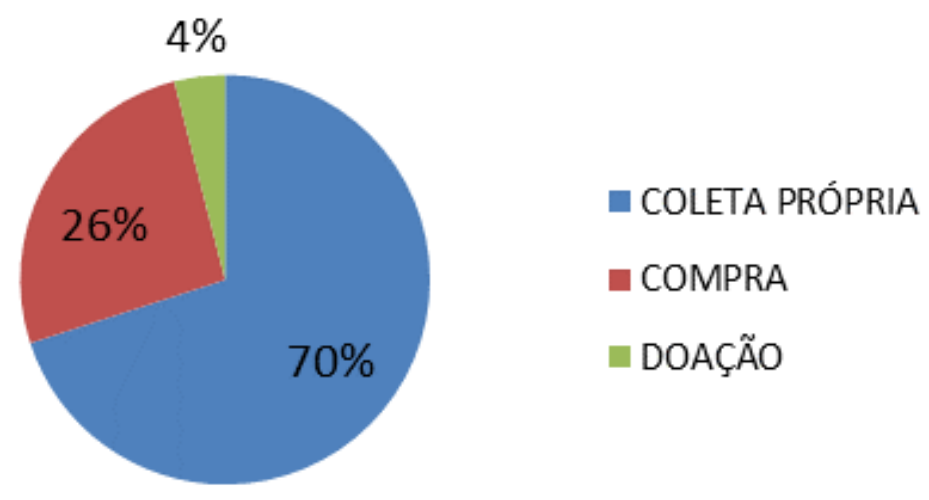

Fonte: Elaboração própria baseada em dados coletados do ano de 2016.

Nos viveiros entrevistados na região metropolitana de Goiânia, onde ocorre compra de sementes, há uma particularidade: apenas quatro produtores de mudas compram suas sementes em grande parte de empresas do 
ramo, principalmente do estado de São Paulo; mesmo assim, em pequena quantidade. A maioria dos produtores compra sementes de coletores autônomos, ainda que em pequena quantidade. Em todas as situações, não há conhecimento da procedência, tampouco dados sobre germinação e vigor das sementes.

A prática de coletar sementes de árvores isoladas ou que compõem a arborização urbana, embora utilizada pelos viveiristas, deve ser evitada. Isso porque essas árvores, geralmente, trocam pólen com poucos indivíduos e têm grande índice de autofecundação, restringindo a diversidade genética do lote de sementes. Esse aspecto pode ocasionar baixas taxas de germinação, mudas com crescimento inferior e com maior suscetibilidade ao ataque de insetos-pragas e doenças (PIÑA-RODRIGUES et al., 2007). Além disso, segundo Sebbenn (2002), para restauração florestal de uma área, as mudas das espécies utilizadas necessitam ter elevada diversidade genética para evitar a endogamia e conservar seu potencial evolutivo, evitando a perda de alelos que pode levar o plantio à depressão endogâmica.

Ainda, o método de coleta utilizado na obtenção das sementes pode ser um bom preditor sobre sua qualidade. Coletas realizadas sem o procedimento adequado podem inviabilizar o uso das sementes. Como exemplo, tem-se a coleta realizada diretamente do chão, em que as sementes podem estar contaminadas por fungos ou ter sido atacadas por insetos, o que pode afetar a sua germinação e, posteriormente, o desenvolvimento das mudas.

O conhecimento sobre a forma de obtenção de sementes é importante, pois consiste em um dos parâmetros para avaliação da qualidade das sementes adquiridas pelos viveiros. Torna-se fundamental saber a procedência das matrizes. Na Figura 5, são apresentados os principais locais de coleta de sementes realizados pelos viveiros pesquisados. 
Figura 5 - Principais locais de coleta de sementes escolhidos pelos viveiros.

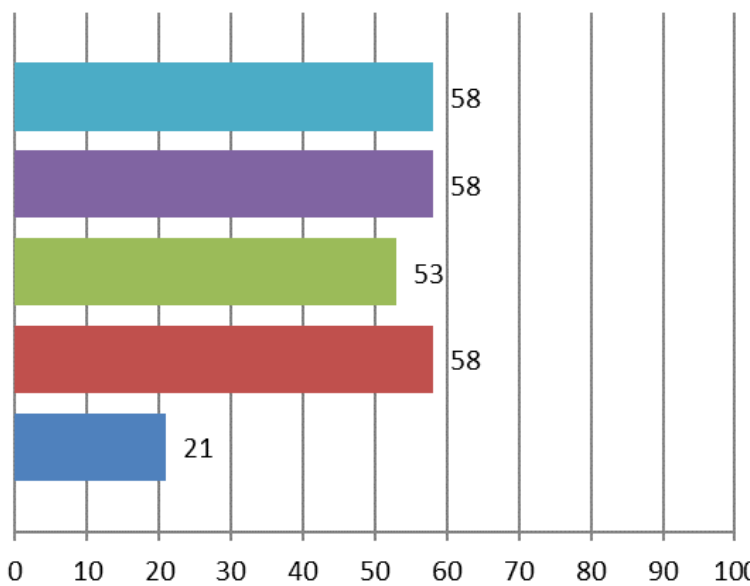

- ARBONIZAÇÃO URBANA

- ÁRVORES ISOLADAS DA REGIÃO

- REMANESCENTE DA REGIÃO

- REMANESCENTE DO VIVEIRO

MATRIZES MARCADAS

Locais de Coleta (\%)

Fonte: Elaboração própria baseada em dados coletanos no ano de 2016.

O perfil dos coletores, segundo os viveiristas, é bem peculiar. São trabalhadores autônomos, vivem de prestar serviços de limpeza e jardinagem e, para aumentar seus rendimentos, coletam pequena quantidade de sementes e as vendem nos viveiros. Os viveiristas, ao serem questionados sobre como ocorre contato com esses coletores, responderam que a compra não é constante, mas sim esporádica. Os coletores não são específicos, há mudança de um ano para o outro. Os próprios coletores oferecem sementes; com isso, não é estabelecido contato frequente com esses trabalhadores.

A IN/MAPA n. 17/2017 ressalta que não é permitido ao coletor comercializar sementes florestais, essa atividade deve ser entendida como uma prestação de serviço ao produtor (beneficiador, armazenador ou comerciante) de sementes. Além disso, o art. 9o da IN/MAPA n. 17/2017 determina que o coletor deve seguir todos os parâmetros técnicos estabelecidos pelo responsável técnico do produtor, sendo vetado a ele a atividade de beneficiar as sementes.

Nota-se que não há local certo de coleta das sementes, por parte dos coletores, podendo ser coletadas em vários locais e matrizes. Cogita-se que esses trabalhadores não têm material adequado de coleta, com coletas de 
sementes diretamente do chão, com beneficiamento e armazenamento de sementes sendo realizados de maneira inadequada. A identificação das espécies é realizada de acordo com seu próprio conhecimento, sem nenhuma forma de comprovação. Ademais, o perfil traçado pelos viveiristas é de que esses coletores não vivem somente dessa atividade e que isso é uma forma de aumentar sua renda, não tendo condições de se cadastrarem na Rede Nacional de Semente e Mudas (RENASEM).

Em relação às coletas de sementes realizadas em matrizes marcadas, apenas quatro viveiros dos 19 produtores coletam dessa forma, especialmente em remanescentes dos viveiros e em propriedades pertencentes aos próprios viveiristas. Esses resultados são semelhantes àqueles encontrados no Espírito Santo e sul da Bahia, em que somente 19\% dos viveiros coletam sementes em árvores matrizes devidamente marcadas e identificadas (RIOESBA, 2007).

Em levantamento realizado pela Rio de Janeiro (2010), em 70 viveiros no estado do Rio de Janeiro, somente seis viveiros coletam sementes em árvores matrizes marcadas e devidamente identificadas, como é recomendado tecnicamente. Outros dez viveiristas declararam ter a maioria das matrizes devidamente marcadas, e em quatro há minoria das matrizes marcadas, nas quais realizam coleta de sementes. Dessa forma, 41 (67\%) viveiros não têm o hábito de marcar matrizes para coleta de suas sementes. Torna-se importante, com os dados obtidos, ter o conhecimento da localização geográfica das matrizes coletadas, pois isso proporciona monitorar a qualidade do material coletado e dá confiabilidade ao comprador, além de proporcionar agregação de valor no produto.

No diagnóstico realizado no estado do Rio de Janeiro, entre os viveiros que utilizam sementes provenientes de coleta própria, verifica-se que 50 (82\%) coletam em fragmentos florestais de Mata Atlântica sitiados próximos das suas áreas de produção de mudas. Ao se considerar que o mesmo viveiro pode realizar a coleta em diferentes locais, verifica-se que 30 (49\%) também utilizam sementes coletadas em remanescentes localizados dentro ou em proximidades do viveiro. Além disso, foi constatado que 25 (41\%) dos viveiros utilizam sementes coletadas em árvores isoladas, isto é, em árvores que não estão dentro de áreas florestais, mas sim em pastagens, 
quintais e outras áreas abertas; e 33 (54\%) coletam sementes de indivíduos que compõem a arborização urbana (RIO DE JANEIRO, 2010).

Com relação à fonte de coleta de sementes, a IN/MAPA n. 17/2017, em seu art. 6으, determina que o produtor de sementes de espécies florestais deverá declarar ao órgão de fiscalização de sua respectiva unidade da Federação a fonte de sementes (localização da área de coleta ou de matriz isolada) de cada espécie que pretenda produzir. A declaração de fonte de sementes terá validade de três anos e deverá ser efetuada nos termos do Anexo IV da IN/MAPA n. 17/2017, acompanhada do roteiro de acesso à fonte de sementes e autorização do detentor dos direitos de propriedade intelectual no caso de cultivares.

Em relação à procedência das sementes utilizadas para a produção de mudas nos viveiros brasileiros, foi observado que grande parte dos viveiristas coleta sua semente no entorno da área de produção. Poucos, entretanto, realizam a marcação de matrizes, não havendo controle em relação ao número mínimo de árvores coletadas e, consequentemente, sem garantia da qualidade genética dos lotes de sementes. Essa situação pode comprometer a sustentabilidade dos reflorestamentos devido ao uso de mudas com alto grau de parentesco e, por isso, com maior suscetibilidade a insetos-pragas e doenças.

A compra de sementes exercida pelos viveiros da região metropolitana de Goiânia, em sua maior parte, é realizada por meio de coletores autônomos (67\%), que realizam as coletas das sementes em matrizes desconhecidas. No diagnóstico realizado por São Paulo (2011), a compra de sementes, por sua vez, é exercida por 111 (54\%) viveiros, sendo que 71 deles são da iniciativa privada. A compra é a principal forma de obtenção de sementes para 54 (26\%) viveiros, 35 deles da iniciativa privada, 13 do terceiro setor e 6 do poder público. Para 9 (4,5\%) viveiros, a coleta e a compra ou troca de sementes são realizadas em igual proporção (50\%). Para apenas um viveiro, o recebimento de sementes por doação é a principal forma de obtê-las.

Um dos gargalos levantados pelos viveiristas é a adoção por parte dos órgãos governamentais de incentivos que promovam a inclusão dos pequenos produtores nessa cadeia. Isso porque o debate não é unicamente sobre 
a adequação à nova lei, mas também sobre quem esta lei atinge e sobre os mercados florestais que podem ser criados a partir dela. Um exemplo desses novos mercados procede da atividade de coleta de sementes que se apresenta informal e com baixa comercialização, principal insumo da cadeia de restauração florestal, utilizada tanto para a produção das mudas como para o uso na semeadura direta.

\section{CONSIDERAÇÕES FINAIS}

- A cadeia produtiva de sementes florestais nativas do Cerrado, na Região Metropolitana de Goiânia, apresenta-se complexa e distante do que visam os órgãos responsáveis por esse setor.

- O acompanhamento dos órgãos responsáveis deve ser mais atuante, no sentido de auxiliar e incentivar os viveiros a seguirem as normativas vigentes, inclusive alterar ou criar novas instruções normativas que facilitem os produtores, seja de sementes, seja de mudas a cumprirem as leis que regem o setor.

- A forma de obtenção das sementes, em sua maioria, é realizada por coleta própria dos produtores, seguida pela compra, que é realizada por meio de coletores autônomos, sem ter nenhum conhecimento da procedência do local de coleta, tampouco sobre como é realizado o beneficiamento e o armazenamento das sementes.

- Torna-se fundamental a criação de leis estaduais, para regimentar o setor de sementes e mudas, que é parte fundamental na restauração florestal. Esse é o caso do estado de Goiás, que tem no agronegócio um grande aporte econômico, em que há desmatamento devido à utilização errada do ambiente, e há locais que necessitam recuperar áreas de preservação permanente e reservas legais.

- Com os problemas detectados, a atividade necessita também de um apoio, por parte dos entes públicos, para disponibilizar algumas árvores matrizes de cada espécie devidamente georreferenciada e que esteja em demanda na atualidade. O incentivo para implantar projetos para produtores de sementes seria uma alternativa para impulsionar a atividade. Uma possibilidade seria a utilização de remanescentes mais conservados 
que estivessem em áreas públicas propícias para coleta de sementes, evitando, assim, coleta predatória.

\section{REFERÊNCIAS}

ALONSO, J. M. Análise dos viveiros e da legislação brasileira sobre sementes e mudas florestais nativas no estado do Rio de Janeiro. 2013. 89f. Dissertação (Mestrado em Ciências Ambientais e Florestais) - Universidade Federal Rural do Rio de Janeiro, Rio de Janeiro, RJ, 2013. Disponível em: http://www.bibliotecaflorestal.ufv.br/ handle/123456789/6907. Acesso em: 21 jan. 2016.

ALONSO, J. M.; SANTOS LELES, P. S.; FILHO., T. B. S.; MESQUITA, C. A. B.; PEREIRA, M. L.; SALES JUNIOR, J. A. S.; ALVES, F. L.; DA SILVA, C. O. Avaliação da diversidade de espécies nativas produzidas nos viveiros florestais do estado do Rio de Janeiro. Floresta, Curitiba, v. 44, n. 3, p. 369-80, 2014. Disponível em: https://revistas.ufpr. br/floresta/article/view/31910/23186. Acesso em: 12 jul. 2017.

BRANCALION, P. H. S. et al. Instrumentos legais podem contribuir para a restauração de florestas tropicais biodiversas. Revista Árvore, Viçosa, v. 34, n. 3, p. 455-70, maio/jun. 2010. Disponível em: http://www.scielo.br/pdf/rarv/v34n3/a10v34n3. Acesso em: 21 nov. 2016.

BRASIL. Decreto n. 5.153, de 23 de julho de 2004. Aprova o Regulamento da Lei n. 10.711, de 5 de agosto de 2003, que dispõe sobre o Sistema Nacional de Sementes e Mudas - SNSM, e dá outras providências. Diário Oficial da União, Brasília-DF, 26 de julho de 2004. Disponível em: http://www.planalto.gov.br/ccivil_03/ato20042006/2004/decreto/d5153.htm. Acesso em: 26 fev. 2016.

BRASIL. Instrução normativa n. 17, de 26 de abril de 2017. Regulamenta a produção, a comercialização e a utilização de sementes e mudas de espécies florestais ou de interesse ambiental ou medicinal, nativas e exóticas, visando garantir sua procedência, identidade e qualidade; revoga a Instrução Normativa n. 56, de 2001, e a Instrução Normativa n. 39, de 2012; e dá outras providências. Diário Oficial da União, Brasília-DF, 28 de abril de 2017. Disponível em: http://www.agricultura. gov.br/assuntos/insumos-agropecuarios/insumos-agricolas/sementes-e-mudas/ publicacoes-sementes-e-mudas/INN17de28042017comANEXOS.pdf. Acesso em: 15 jun. 2017.

PIÑA-RODRIGUES, F. C. M.; FREIRE, J. M.; LELES, P. S. S.; BREIER, T. B. Parâmetros técnicos para a produção de sementes florestais. Seropédica: UFRRJ, 2007. Disponível em: https://www.researchgate.net/profile/Fatima_Pina_ 
Rodrigues/publication/232768854_Parametros_tecnicos_para_a_producao_ de_sementes_florestaisTechnical_parameters_to_forest_seed_production/ links/Ofcfd50954abb9ff5e000000.pdf. Acesso em: 10 dez. 2015.

REDE DE SEMENTES FLORESTAIS DA MATA ATLÂNTICA [RIOESBA]. Diagnóstico dos viveiros de produção e mudas nativas da Mata Atlântica existentes nos estados da Bahia e Espírito Santo. Rio de Janeiro: Rede de Sementes Rio/São Paulo, 2007. 30 p.

RIO DE JANEIRO (Estado). Secretaria do Estado do Ambiente do Rio de Janeiro [SEA]. Diagnóstico da produção de mudas de espécies nativas do estado do Rio de Janeiro. [Relatório técnico]. Rio de Janeiro: Governo do Estado do Rio de Janeiro, 2010. 63 p. Disponível em: http://www.itpa.org.br/wp-content/uploads/ diagnostico_mudas_VF.pdf. Acesso em: 10 de jun. 2015.

SEBBENN, A. M. Número de árvores matrizes e conceitos genéticos na coleta de sementes para reflorestamentos com espécies nativas. Revista do Instituto Florestal, São Paulo, v. 14, n. 2, p. 115-32, 2002. Disponível em: https://www. researchgate.net/profile/Alexandre-Sebbenn/publication/256652269_SEBBENN AM_Numero_de_arvores_matrizes_e_conceitos_geneticos_na_coleta_de_ sementes_para_reflorestamentos_com_especies_nativas_Revista_do_Instituto_Fl orestal_v_14_n_2_p_115-132_2002/links/559bde5708aee2c16df0271f/SEBBENNAM-Numero-de-arvores-matrizes-e-conceitos-geneticos-na-coleta-de-sementespara-reflorestamentos-com-especies-nativas-Revista-do-Instituto-Florestal-v-14-n2-p-115-132-2002.pdf. Acesso em: 2 fev. 2016.

SILVA, A. P. M.; MARQUES, H. R.; SANTOS, T. V. M. N.; TEIXEIRA, A. M. C.; LUCIANO, M. S. F.; SAMBUICHI, R. H. R. Diagnóstico da produção de mudas florestais nativas no Brasil. Brasília: Instituto de Pesquisa Econômica Aplicada [IPEA], 2015. 58 p. [Relatório de Pesquisa]. Disponível em: http://www.ipea.gov.br/portal/images/ stories/PDFs/relatoriopesquisa/150507_relatorio_diagnostico_producao.pdf. Acesso em: 5 jan. 2016.

SÃO PAULO (Estado). Secretaria do Meio Ambiente de São Paulo [SMA]. Diagnóstico dos produtores de mudas florestais nativas do estado de São Paulo. São Paulo: Governo de São Paulo, 2011. 155 p. [Relatório analítico]. Disponível em: http://www.sigam.ambiente.sp.gov.br/sigam3/Repositorio/222/Documentos/ Produtos\%20Tecnicos/Produtos_Tecnicos_02_viveiros.pdf. Acesso em: 12 jul. 2016. 